\title{
The future of end-of-life vehicles (elv) in Malaysia - A feasibility study among car users in Klang valley
}

\author{
Zulhaidi Mohd Jawi ${ }^{1, *}$, Mohd Hafzi Md Isa ${ }^{1}$, Mohd Syazwan Solah ${ }^{1}$, Aqbal Hafeez Ariffin ${ }^{1}$, \\ Akmalia Shabadin ${ }^{2}$ and Mohd Rasid Osman ${ }^{1}$ \\ ${ }^{1}$ Vehicle Safety \& Biomechanics Research Centre (VSB), Malaysian Institute of Road Safety \\ Research (MIROS), 43000 Kajang, Selangor, Malaysia \\ ${ }^{2}$ Road Safety Engineering \& Environment Research Centre (REER), Malaysian Institute of Road \\ Safety Research (MIROS), 43000 Kajang, Selangor, Malaysia
}

\begin{abstract}
In its bid to become a developed nation in a few years' time, Malaysia has to consider various prevailing socio-economic and sociotechnical issues in the country. In the transportation sector per se, the ELV policy and initiative is one of the lacking parts in the country's automotive ecosystem - in which a successful ELV program will not only cater the environmental concern but also help the safer car initiative for road users. This particular paper discusses what is regarded as the preliminary findings on the ELV policy from the Malaysia's automotive ecosystem study database. From a total of 484 respondents, 268 or $55.4 \%$ had agreed to the proposal to introduce an age limit for passenger vehicles in Malaysia. The majority of those who gave their nod to the policy choose 10 years of vehicle age as the limit (38.9\%), and a staggering $79.8 \%$ of them supposed that the age limit should be between 5 to 10 years. Further analysis based on the Multiple Logistic Regression found out that from a total of nine important variables related to car users' profile and ownership status, the significant predictors to "the agreement to introduce vehicle age limit" were age, income and car status (new or used). Thus, this finding might be beneficial for the policymakers to strategize the ELV policy that sooner or later should be implemented in the Malaysia's "developed country" environment.
\end{abstract}

\section{Introduction}

In Malaysia's road transportation layout, private vehicles, in which the majority are cars and motorcycles, play an important role in everyone's daily routine. Since the public transport oriented mobility in the country is still not at satisfactory level according to the world's standard, both motorcycles and cars are the most convenient options for the daily commuting needs [1]. The motorcycles provide the economic option for mobility, while cars offer the comfort of a four-wheeler and technically more safety features than motorcycles [2]. Though there are many other reasons for someone to own car and/or

* Corresponding author: zulhaidi@miros.gov.my 
motorcycle, the users in general regard the ownership of car as a symbol of success. In fact, according to the Nielsen Global Survey of Automotive Demand, Malaysians and users in other ASEAN countries have that particular believe, in which the rate is above the world's average of $52 \%$ [3].

For example, Malaysian users' obsession towards cars can be seen in the registration plate number popularity, in which some car owners have exceptional feeling and willingness to have the "stylish" and "meaningful" ones. It perhaps a big surprise to the non-Malaysians to know that prior to the introduction of " $F$ " series, there were two highest bidding so far in the Road Transport Department (RTD) history [4]. They were "W 1 N" that symbolizes the word "WIN" (MYR 748,000 or about USD 200,000) and "WWW 1" that is linked to the internet's World Wide Web (MYR 520,000 or about USD 130,000). Also, it is expected that the recently launched " $F$ " series registration number plate will contribute multi-million ringgits to the government revenue through RTD, in which the number "F1" will be the main target [4].

Furthermore, based on the abovementioned Nielsen's study, car ownership among Malaysians is not only the highest in the ASEAN but also has the highest incidence of multiple car ownership. It is reported that $54 \%$ of Malaysian households own more than one car. The abovementioned fact perhaps is adequate to explain the reason behind the high demand of both new and used cars in the country. According to the Total Industry Volume (TIV) in 2015, more than 660,000 new vehicles (including commercials) were sold and approximately $89 \%$ of that figure were new cars [5].

The sales of new cars that is stable and in ever-increasing trend seems contradict to the fact that Malaysia is among the countries that have high car prices [6]. Moreover, it is observed that the car users today have high willingness to own the so-called "non-national" cars that are essentially more expensive than the local marque, Proton and Perodua, due to the different taxing system. Though Perodua and Proton hold the biggest market share at around $47 \%$ in 2014 and 2015, the domination is actually in a downward trend from as high as $80 \%$ in the year 2000 [7]. In fact, the TIV shares among the non-national makes in 2014 had exceeded the $50 \%$ mark for the first time after decades i.e. since the establishment of Proton (1985) and Perodua (1993) [8].

Moreover, the Malaysia Automotive Institute (MAI) reckoned that Malaysia is the second cheapest country in the ASEAN region to own a vehicle after the Philippines despite the high car prices [9]. This is largely due to the relatively low fuel prices (previously subsidized), cheaper road tax and insurance premium - thus making the cost of vehicle ownership (CVO) at a very competitive figure. Even in a non-subsidized fuel scenario, the CVO would rank third as compared with its ASEAN counterparts and still cheaper than Thailand and Indonesia [9].

Nevertheless, it is quite unfortunate that the End-of-Life Vehicles (ELV) policy has never taken place in the system $[2,10]$. By looking at the automotive world from a bigger picture, the current automotive ecosystem in Malaysia can be considered as incomplete or "unhealthy" (Figure 1) [2]. A car may only permanently or legitimately retire due to other reasons such as not roadworthy beyond economic repair or due to road accidents (premature ELV), rather than guided by a solid systemic intervention to produce a "healthy" system through ELV initiatives. Donella H. Meadows [11] mentioned about the dynamics of stocks and flows in order to understand the behaviour of complex systems using water in the bathtub as an example. If the bathtub is filled with water, its drain plugged up and its faucets turned off, it will produce an unchanging, not dynamic, and boring system (Figure 2). In the case of automotive ecosystem in Malaysia, the cars keep coming into the "tub" and there is no proper outflow from the system that raises two main concerns - environmental and safety issues. 


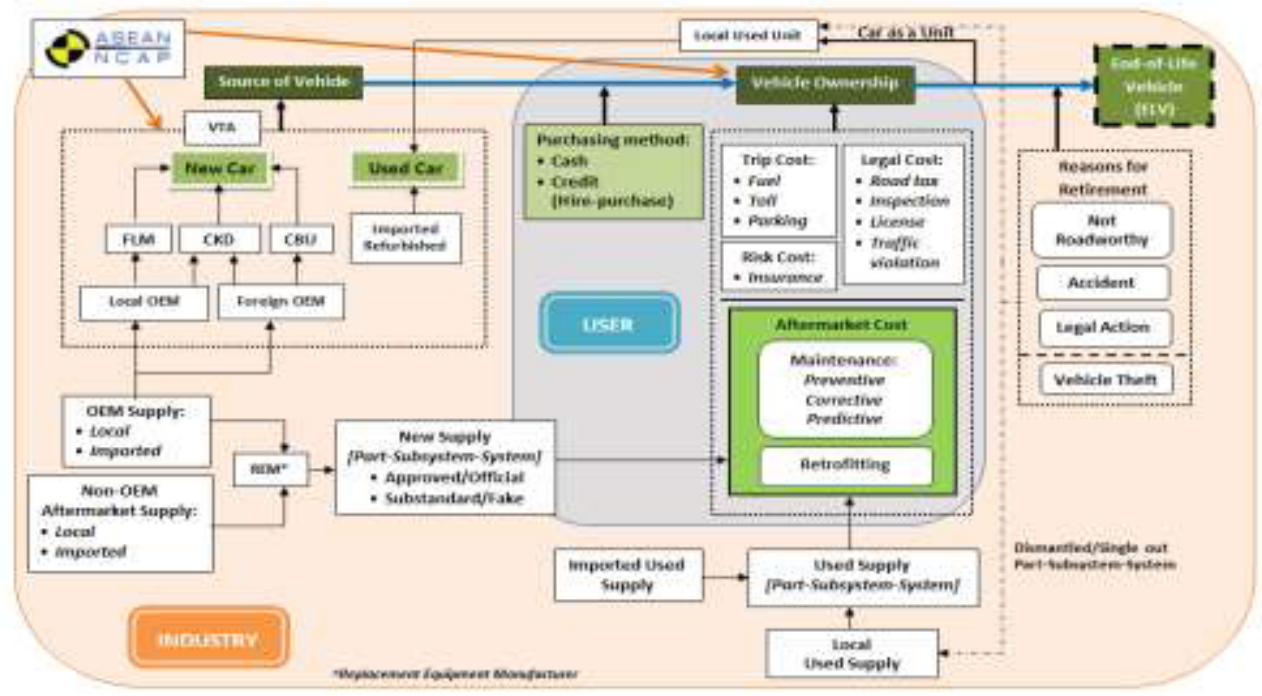

Fig. 1. The automotive ecosystem in Malaysia [2].

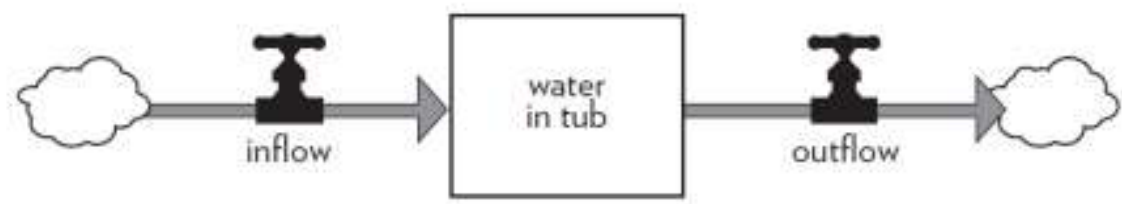

Fig. 2. Understanding complex systems using water in tub example [11].

A proper ELV plan can contribute to sustainable environmental control through the 3R's concept - Reduce, Reuse and Recycle [12]. The concept can be further elaborated into 6R's - Reduce, Reuse, Recycle, Recover, Remanufacture and Redesign - in which it signifies how extensive a proper ELV plan could achieve [12]. For example, certain countries had managed to reach more than $80 \%$ in recovery rate [13]. ELV could also help car maintenance by reusing parts or components that are obviously cheaper than new items [14].

Furthermore, aged car is not only deteriorating in its roadworthiness but also in the element of safety such as the body strength. Aged car also could not compete with newer cars that are equipped with latest technologies in both passive (better built and crashworthiness design element) and active safety (e.g. stability control). Thus, in an ideal environment, the old cars should be replaced by new cars by motivating the consumers to buy new cars and the ELV system forces aged or not roadworthy cars to retire.

This is how the safer vehicles initiative through New Car Assessment Program (NCAP) such as ASEAN NCAP and Vehicle Type Approval (VTA) by the Road Transport Department (RTD) can gradually "clean up" the system i.e. new cars that are generally safer than the old ones will replace the existing cars in the system [2]. Effective ELV policy also will be the catalyst to create more demand in new car market and the policy will efficiently "flush out" bad cars from the system. Consequently, the more the number of safer cars in the system may significantly reduce the probability of accidents to occur (mainly active safety) as well as the related injuries by virtue of the better protection in the more modern cars (passive safety). 
The Malaysian government had once proposed the "gradual introduction of ELV policy" in the revised National Automotive Policy (NAP) in 2009 but immediately had taken it down due to public uproar upon the announcement [14]. Additionally, the latest version of NAP (2014) had changed its focus to "green vehicle" via the Energy Efficient Vehicle (EEV) scheme and complemented by the Voluntary Vehicle Inspection Policy (VVIP), which can be seen as a less superior move as compared to the controversial "fullscale ELV policy" [13]. Other than that, the government had once conducted the vehiclescrappage subsidy program but that was merely under the economic stimulus exercise rather than a pure introduction to a permanent ELV structure [13].

It perhaps unique for Malaysia that any new changes to the so-called "routine" in the society will create an instant public uproar and negative perception, though the initiatives are for the better future of the country - economically and environmentally. This recently happened in the introduction of Goods and Services Tax (GST) to replace the old tax system [15], the introduction of Automated Enforcement System (AES) for speeding and red light running offences [16], as well as in the ELV issue [2].

Thus this paper discusses what is regarded as the preliminary findings on the ELV policy from the Malaysia's automotive ecosystem study database. The main aim of this paper is to explore the car users' opinion on the proposal to introduce an age limit to passenger vehicles in the country. Furthermore, it is important to understand the acceptance level of the most important stakeholders in the automotive ecosystem, i.e. the users, so that policymakers can better strategize the ELV policy that sooner or later should be implemented in the Malaysia's “developed country” environment in the year 2020.

\section{Methodology}

The data used in this paper was taken from the "automotive ecosystem" study's database, in which the effort started as a research cluster at MIROS in 2011. The most recent work in this subject was the cross-sectional self-administered survey done in Klang Valley under the theme of "automotive consumerism". In the abovementioned survey, the eligible respondents were those who owned cars and residing or commuting in the Klang Valley conurbation (or coined as Greater KL since 2010). It was a fairly lengthy questionnaire that consist of six sections and a total of 12 sub-sections.

The data was collected through five different approaches i.e. at public places, offices, industrial areas, schools (for teachers) and car clubs. A total of 500 responses were collected in a period of approximately a year (June 2015 to June 2016), and it is worth to mention that several sub-sections suffered a considerable amount of missing data due to a number of reasons such as the respondents' unfamiliarity with the formal or technical terms in automotive (e.g. NCD for No Claim Discount in car insurance), or they did not aware of certain items asked in the survey (e.g. all about cars are taken care by spouse).

Therefore, this paper would like to present the analysis on the final section of the survey, which is on the respondents' opinion on ELV initiative. The first part of the survey (ELV section) asked whether or not they will agree if there will be a law on vehicle age limit to be implemented in the country, and those who answered "Yes" was asked for the specific age that they think deemed suitable for the law. Simple Logistic Regression (SLR) analysis was conducted to determine the significance of individual predictors based on the car users' profile and ownership status towards "the agreement to vehicle age limit (ELV)" policy. Further analysis using the Multiple Logistic Regression (MLR) analysis was conducted to identify the significant variables using backward elimination method. The variable that has the $\mathrm{p}$-value less than 0.05 was considered as significant variable(s). 


\section{Results and discussion}

From a total of 484 valid responses with regard to the ELV section, 324 or $67 \%$ of the respondents were males and the majority of them were from the Malay ethnicity $(85.5 \%)$ (Table 1). Also, most of the respondents were married (67.6\%), had post-secondary level or tertiary education (combined percentage of $79 \%$ ), worked at the private or GovernmentLinked Companies (GLC) sector (59.3\%), had the monthly income below MYR 5,000 (approx. USD 1,250 at 4.00 exchange rate) (75.6\%), owned only one car (74.4\%), and using the cars that were bought as new $(71.9 \%)$.

Furthermore, out of 484 valid responses, 268 (55.4\%) of the respondents had agreed to the proposal of having a law on vehicle age limit in the country as part of the ELV solution. The majority of those who gave their nod to the policy choose 10 years of vehicle age as the limit (38.9\%), and a staggering $79.8 \%$ of them supposed that the age limit should be between 5 to 10 years. Simple Logistic Regression analysis has been done to identify the important variables to predict the agreement to the vehicle age limit policy. Based on Table 1, the significant variables are: age, marital status, education level, income level (monthly) and car status.

The abovementioned five variables that are statistically significant in the Simple Logistic Regression were used in the Multiple Logistic Regression analysis. Out of the five variables, only three are significant, which are age, income and car status (Table 2). The model is a good fit since the significance value for Hosmer and Lemeshow Test is 0.305, which is greater than 0.05 . There is also no multicollinearity among the independent variables.

The analysis demonstrated that the buying-in process for the implementation of ELV policy may very well accepted by those with higher income level. It is just a logical observation that users with higher income will prefer better and safer cars since they have the financial freedom to buy and "upgrading" cars. With the rising in income level among the users, Malaysians have the high tendency to upgrade their vehicle when they are financially able - at $93 \%$, which is above the world's average at $89 \%$ [3]. In terms of car status, those who own the cars that they bought as "new" are having higher preference for ELV than the owners of used cars. Furthermore, the age factor is significantly decreasing towards older users - even though the impact might not be as big as the abovementioned factors.

The educational approach can also be considered as an additional catalyst in the buyingin process. Though the education level in not statistically significant in the Multiple Logistic Regression analysis, those with higher level of education (under- and postgraduate degree) had higher tendency to support the ELV initiative in the univariate analysis. According to D.A. Wahab and Z.F. Fadzil [17], the knowledge of the public community in Malaysia is at a fairly good level in terms of recycling and reuse of solid waste, but the knowledge on specific endeavors in environmental issues (specific ELV approach) is low. Thus, the educational approach must be done continuously with regard to the understanding of environmental-friendly automotive waste disposal via ELV framework.

According to Shameem et al. [13], the government must be ready to implement several strategies in order to build a solid ELV structure in Malaysia i.e. ELV recycling law, proper deregistration process and destruction permit, comprehensively aided remanufacturing activities, active research in policies and technologies, as well as collaborative effort among the government agencies and local authorities. Nevertheless, the public acceptance is another challenge to the government, especially when it is involved financial capacity. For example, certain ELV practice elsewhere need the user to pay for the disposal process either prior to car ownership (paid by first owner) or at the end of the car's life (paid by last owner) [18]. As mentioned earlier, any new changes in the society that incur additional cost 
to the users will not be a popular move, and yet the scrappage subsidy program is neither a sustainable option in the long run for the government. Therefore, it is important to monitor users' acceptance towards the Voluntary Vehicle Inspection Policy (VVIP) in order to indirectly gauge the growth in ELV awareness.

Table 1. Unadjusted odds ratio with $95 \%$ Confidence Interval (CI).

\begin{tabular}{|l|c|c|c|}
\hline \multicolumn{1}{|c|}{ Factor } & N (\%) & Unadjusted OR (95\% CI) & p-value \\
\hline Gender & & & \\
\hline Female & $160(33.1)$ & & \\
\hline Male & $324(66.9)$ & $0.726(0.494,1.067)$ & 0.103 \\
\hline Race & & & \\
\hline Malay & $414(85.5)$ & & 0.175 \\
\hline Non-Malay & $70(14.5)$ & $1.435(0.852,2.419)$ & $<0.05$ \\
\hline Age & & $0.978(0.958,0.999)$ & \\
\hline Marital Status & $151(31.2)$ & & $<0.05$ \\
\hline Single & $327(67.6)$ & $0.654(0.441,0.971)$ & 0.054 \\
\hline Married & $6(1.2)$ & $0.118(0.013,1.035)$ & \\
\hline Single Parent & & & 0.326 \\
\hline Education & $101(20.9)$ & & $<0.05$ \\
\hline Primary, Secondary \& & & \\
\hline Not Attended School & $143(29.5)$ & $1.293(0.774,2.160)$ & \\
\hline Cert/Dip/STPM & $196(40.5)$ & $2.428(1.486,3.966)$ & \\
\hline Degree & $44(9.1)$ & $2.608(1.247,5.453)$ & \\
\hline Post Graduate & & & 0.450 \\
\hline Job & $118(24.4)$ & & 0.982 \\
\hline Government & $287(59.3)$ & $1.181(0.767,1.817)$ & \\
\hline Private/GLC & $47(9.7)$ & $0.992(0.504,1.953)$ & \\
\hline Self-Employed & $32(6.6)$ & $0.770(0.352,1.685)$ & 0.514 \\
\hline Others & & & 0.379 \\
\hline Monthly Income & $201(41.5)$ & & $<0.05$ \\
\hline$<$ RM 3000 & $165(34.1)$ & $0.807(0.534,1.219)$ & \\
\hline RM 3001 - RM 5000 & $67(13.8)$ & $1.574(0.889,2.786)$ & \\
\hline RM 5001 - RM 8000 & $49(10.1)$ & $2.709(1.335,5.496)$ & \\
\hline > RM 8000 & $360(74.4)$ & & \\
\hline No. of Car(s) & $105(21.7)$ & $0.860(0.556,1.330)$ & \\
\hline One car & $19(3.9)$ & $1.075(0.423,2.737)$ & \\
\hline Two cars & $136(28.1)$ & & \\
\hline Three or more cars & $348(71.9)$ & $1.731(1.161,2.582)$ & \\
\hline Car Status & & & \\
\hline Used & & & \\
\hline New & & & \\
\hline
\end{tabular}

Note: Columns do not add to totals due to missing data

Table 2. Adjusted odds ratio with $95 \%$ Confidence Interval (CI)

\begin{tabular}{|l|c|c|}
\hline \multicolumn{1}{|c|}{ Factor } & Adjusted OR (95\% CI) & p-value \\
\hline Age & $0.956(0.932,0.980)$ & $<0.001$ \\
\hline Income & & \\
\hline < RM 3000 & & \\
\hline RM 3001 - RM 5000 & $0.877(0.569,1.350)$ & 0.551 \\
\hline RM 5001 - RM 8000 & $1.998(1.084,3.684)$ & $<0.05$ \\
\hline > RM 8000 & $4.578(2.096,9.997)$ & $<0.05$ \\
\hline Car Status & & \\
\hline Used & $1.892(1.245,2.874)$ & $<0.05$ \\
\hline New & & \\
\hline
\end{tabular}




\section{Conclusions}

A proper End-of-Life Vehicles (ELV) plan can contribute to sustainable environmental control as well as in promoting safety in the more modern cars. It is quite unfortunate that the ELV policy has never taken place in the Malaysia's automotive ecosystem and therefore the current ecosystem can be considered as incomplete or "unhealthy". The analysis of the data from the Malaysia's automotive ecosystem study database has shown that the government has to face certain challenges with regard to the users in implementing the ELV policy in the country. Though the slight majority of the respondents in this particular study had agreed to the idea of vehicle age limit law, the preference is largely driven by the users' economic stability (income level and car status) and age factor. Thus, the government has to consider these users' influences in developing the ELV policy that sooner or later is needed in the targeted developed country environment.

The authors would like to express their gratitude to those who had given support during the data collection, as well as during the analysis and report writing stage. Special mention goes to the Director-General of MIROS, Prof. Dr. Wong Shaw Voon and the Research Management and Compliance (RMC) Unit, for the opportunity and guidance in completing the main project, "Understanding Car User's Practices \& Behaviour in a Proposed Conceptual Framework of Automotive Consumerism" under the grant no. VS102077.

\section{References}

1. A.N.N.A. Rahman, Z.M. Yusoff, D. Omar, I.S. Aziz, Travel to work patterns of lowincome people in urban area, J. Tek., 71, 63-66 (2014)

2. Z. Mohd Jawi, K.A. Abu Kassim and A.F. Sadullah, ASEAN NCAP - The best bet for vehicle safety in the region's safe system? Int. J. of Trade, Econ. \& Fin., 4, 358-363 (2013)

3. Nielsen, Rising middle class will drive global automotive demand in the coming two years, 16 April 2014, Accessed in January 2016, from http://www.nielsen.com/

4. S. Tamrin, RM5m bid for ' F1' number plate, 14 June 2016, Accessed in June 2016, from http://www.thesundaily.my/news/1838787

5. G. Chin, 2015 Malaysia vehicle sales market review, by brand, 21 January 2016, Accessed in February 2016, from http://www.paultan.org/

6. L.H. Toh, Straight Talk: Factors driving up motor vehicle ownership, 5 October 2009, Accessed in January 2016, from http://www.theedgemalaysia.com/

7. F. Mashahadi, M.G. Mohayidin, Consumers' buying behaviour towards local and imported cars: An outlook after the implementation of AFTA in Malaysia, OUM Int. J. of Bus. \& Mgmt., 1(1), 44-54 (2015)

8. D. Tan, Malaysia vehicle sales data for March 2016 by brand, 25 April 2016, Accessed in April 2016, from http://www.paultan.org/

9. CBT, Malaysian car ownership cost is second lowest in South-East Asia - MAI, 16 February 2012, Accessed in February 2016, from http://www.cbt.com.my/

10. L. Amelia, D.A. Wahab, C.H. Che Haron, N. Muhamad, C.H. Azhari, Initiating automotive component reuse in Malaysia, J. of Cleaner Prod., 17, 1572-1579 (2009)

11. D.H. Meadows, Thinking in Systems - A Primer (Earthscan, London, 2009)

12. M.Z. Mat Saman, N. Zakuan, G. Blount, Design for end-of-life value framework for vehicles design and development process, J. of Sust. Dev., 5, 95-111 (2012)

13. S. Ahmed, S. Ahmed, M.R.H. Shumon, M. Abdul Quader, End-of-Life Vehicles (ELVs) management and future transformation in Malaysia, J. of App. Sc. \& Agri., 9 (18), 227-237 (2014) 
14. Z. Mohd Jawi, F. Lamin, A.R. Abdul Manap, K.A. Abu Kassim, F. Abbas, S.V. Wong, Review of the National Automotive Policy on Car Maintenance Issues: Malaysia's Automotive Ecosystem Explained (MIROS, Kuala Lumpur, 2012)

15. S.C. Ling, A. Osman, A.B. Arman Hadi, A. Muhammad Safizal, S.M. Rana, Public acceptance and compliance on Goods and Services Tax (GST) implementation: A case study of Malaysia, Asian J. of Soc. Sc. \& Hum., 5(1), 1-12 (2016)

16. Y. Ghani, M. Musa, Have you heard of 'AES' lately? in Conference of ASEAN Road Safety (CARS), 220-225 (2015)

17. D.A. Wahab, Z.F. Fadzil, Public community knowledge on reuse of End-of-Life Vehicles: A case study in an automotive industrial city in Malaysia, J. of App. Sc., 14(3), 212-220 (2014)

18. N. Kanari, J.L. Pineau, S. Shallari, End-of-Life Vehicle Recycling in the European Union, Overview: Recycling (2003) 